\title{
Is gating an on-line task? Evidence from naming latency data
}

\author{
LORRAINE K. TYLER \\ Max-Planck-Institut für Psycholinguistik, Nijmegen, The Netherlands \\ and MRC Applied Psychology Unit, Cambridge, England \\ and \\ JEANINE WESSELS \\ Max-Planck-Institut fü Psycholinguistik, Nijmegen, The Netherlands
}

\begin{abstract}
We investigated the suitability of the gating task for studying the on-line process of spoken word recognition. To do this, we compared two different versions of the task. In one version, subjects were placed under no time constraints, and in the other, they were encouraged to respond as rapidly as possible. Target words occurred either in isolation or in various types of syntactic and semantic contexts. These different contexts had the same effect on word recognition whether subjects responded within $500 \mathrm{msec}$ of fragment offset or without time constraints. We conclude that both versions of the task are as sensitive as other on-line tasks to the real-time processes involved in spoken word recognition.
\end{abstract}

To investigate the process of spoken word recognition, we need to determine exactly what analyses the listener can perform on the speech input as it accumulates over time. This relationship between the types of analyses performed and the point in time at which they are performed is crucial for the development of a theory that specifies the sequence of mental events involved in recognizing spoken words.

To specify this on-line relationship we need to use experimental tasks in which the listener's response can be closely tied to particular stretches of the speech input. These tasks typically require the listener to produce a fast response to a stimulus in order to achieve a close temporal relationship between input and response. This enables the researcher to determine reasonably precisely what the listener has heard up to the point at which he or she makes a response, and to infer what types of analyses must have been performed on the input to produce the effects reflected in the response. The closer in time a response is to the relevant stretches of the speech input (i.e., the faster the reaction time), the more closely we can specify the properties of the internal processes involved.

The purpose of our study was to investigate the suitability of the gating task for the study of the on-line relationship between input and analysis. In the standard version of the task, listeners hear successively larger fragments of a target word, with each fragment increas-

We wish to thank William Marslen-Wilson, François Grosjean, and David Pisoni for helpful comments on the manuscript. The first author is now at: Department of Psychology, University of Cambridge, Downing Street, Cambridge, England CB2 2EF. ing by some constant amount from word onset (Cotton \& Grosjean, 1984; Grosjean, 1980; Salasoo \& Pisoni, 1985; Tyler \& Wessels, 1983). ${ }^{1}$ If, for example, fragments are incremented in 50-msec steps, the first fragment will consist of the first $50 \mathrm{msec}$ of the word, the second of the first $100 \mathrm{msec}$, and so on, until the whole word has been presented. After hearing each fragment, subjects write down the word they think they have heard and indicate how confident they are.

This is an on-line task in the crucial sense that listeners' responses can be directly related to specific stretches of the speech input. The experimenter knows the amount of sensory input a subject hears at each successive gate and can tie this to the response produced. Although subjects do not have to respond quickly, they do not gain any additional sensory input by waiting, so their respones cannot be contaminated by later stretches of speech. ${ }^{2}$

Furthermore, as an on-line task, gating has significant advantages over standard reaction time (RT) tasks because it gives us two kinds of information about the processes involved in recognizing spoken words. It gives us not only quantitative information about how much of the speech input listeners have heard when they make a response, but qualitative information in the form of the correct or incorrect words subjects produce at each gate. These responses can be analyzed for their compatibility with the acoustic-phonetic input, the prior context (when present), and so forth. This enables us to build up a picture of the changing state of the system as the speech input accumulates over time (Grosjean, 1980; Salasoo \& Pisoni, 1985; Tyler, 1984).

The potential problem with the standard gating task as a measure of on-line performance is that subjects are not forced to make a rapid response to the speech input. In 
the standard version of the task, subjects are given several seconds to simply write down their responses. This leaves the task open to the criticism that these responses do not reflect real-time analyses of the sensory input. The effectively unlimited time that subjects have available to produce a response allows them to reflect consciously upon their word choices, thereby potentially turning the task into one which reflects postperceptual metalinguistic processes rather than the automatized "core processes" (see Marslen-Wilson \& Tyler, 1981) involved in language understanding.

Before addressing this problem, we should deal with another common objection to gating as an on-line measure-namely, that because each subject hears successive presentations of increasingly larger fragments of the same word, responses are significantly distorted. This possibility has been ruled out by the recent results of Cotton and Grosjean (1984) and Salasoo and Pisoni (1985). Cotton and Grosjean compared the multiple-presentation format with a format in which each subject heard only one fragment from each word. They found that this had no effect on the timing with which subjects produced a target word. Salasoo and Pisoni also found no effect of presentation format on the earliness with which words were identified in a meaningful context. The average amount of sensory input needed for correct identification of a word was $161 \mathrm{msec}$ for the successive-presentation format and $166 \mathrm{msec}$ for the single-presentation format. These two studies have established that presentation format does not affect the general pattern of responses obtained in the gating task.

What we will address here is the remaining potential problem for the gating task as an on-line task. Does having unlimited time affect subjects' responses? When they do not have to make a rapid response, do subjects think about their word choices differently, so that their responses do not reflect the sequential analysis of the sensory input to the same extent as they might in a task in which the relationship between input and response was more tightly constrained? For example, it has been argued that context functions only after a word has been accessed (Forster, 1979), and therefore context effects should be observed only in tasks that produce a lag between the automatic processes involved in recognizing a word and the subject's response. If this is the case, interactions observed between context and word recognition in the gating task (Grosjean, 1980; Salasoo \& Pisoni, 1985; Tyler \& Wessels, 1983) might just be due to the long lag between input and response, during which time subjects can assess their word choices against contextual specifications. If subjects are not allowed this time, but are forced to make a rapid response, such interactions might disappear.

To determine if this was the case, we compared data obtained in the standard gating task with data obtained when, in response to a fragment, subjects named the word they thought they were hearing. If subjects' naming times were as fast as responses obtained in other reaction-time tasks that are assumed to reflect on-line processes, we could be fairly confident that this timed version of the task was also sensitive to on-line processes. And if, in turn, the nontimed version of the task also reflected the immediate processes involved in word recognition, then the general pattern of responses in both timed and nontimed versions should be similar. Words should be identifeid at the same point, and the relative effectiveness of different types of context in reducing the amount of sensory input needed for a word's identification should remain the same across tasks.

In the nontimed gating task, the point at which a word is identified has been estimated in two ways. The "isolation point" (IP) is the point at which subjects correctly identify a word and do not subsequently change their minds (Grosjean, 1980; Salasoo \& Pisoni, 1985; Tyler \& Wessels, 1983). The "recognition point" (RP) takes into account the degree of confidence the subject has in his or her word choice (Tyler \& Wessels, 1983). In order to comprehensively compare timed and nontimed data, we use both of these estimates in the present study.

The fragments used in this study were a subset of those used in our earlier experiment (Tyler \& Wessels, 1983), in which they were presented in the successive presentation format. In both studies, fragments occurred either in a no-context condition or in various types of sentential context. In the present experiment, subjects were required to identify a fragment as rapidly as possible; therefore, they could be presented with only a single fragment of each word.$^{3}$ This ensured that subjects did not have time to reflect upon the identity of a fragment while they were waiting for the next fragment of the same word to be presented. Therefore, the design of this study differs from that of our previous study in two ways: subjects were presented with a single fragment, and they were encouraged to produce a response (which was timed) as rapidly as possible.

\section{METHOD}

\section{Subjects}

The subjects were 150 native speakers of Dutch.

\section{Materials}

Seventeen of the target words ${ }^{4}$ and all of the fillers used in the original study (Tyler \& Wessels, 1983) were used in this experiment. All items were presented in their original order. ${ }^{5}$ For each target word (which was always a verb), there were four sentence pairs, with the target in the second sentence of each pair. In two pairs the wording was semantically anomalous and could not semantically facilitate identification of the target. In the other two, the wording up to the target provided a minimal semantic context for the target. 6

We also manipulated syntactic constraints by varying local restrictions on form class. The weak syntactic constraint condition placed minimal constraints on the form class of the target-only certain inflected forms of verbs were prohibited. In contrast, in the strong syntactic constraint condition (which was the most syntactically constraining that Dutch allowed) the target was preceded by the word te, which can be followed only by an infinitive or by one of a small number of adjectives. 
This generated four experimental conditions: (1) minimal semantic context/strong syntactic constraints; (2) minimal semantic context/weak syntactic constraints; (3) anomalous/strong syntactic constraints; (4) anomalous/weak syntactic constraints. In a fifth condition, the target word appeared without any supporting context. ${ }^{7}$

For each item in each of the five conditions, we selected five fragments from the original tapes as test fragments. ${ }^{8}$ One fragment corresponded to the isolation point (as calculated in the nontimed study), the second to the isolation point minus $50 \mathrm{msec}$, the third to the isolation point minus $100 \mathrm{msec}$, the fourth to the isolation point plus $50 \mathrm{msec}$ and the fifth to the isolation point plus $100 \mathrm{msec}$. A timing pulse was placed at the onset of each fragment on the nonspeech channel of the tape. Each pulse started a timer which was stopped when the subject named the fragment.

\section{Design and Procedure}

Since each subject could hear only a single fragment for each test item, 25 versions of the materials were constructed ( 5 conditions $\times 5$ fragments per item). Six subjects were tested on each version. They were tested individually in a quiet room. The subjects heard the materials over headphones and were instructed to name aloud as rapidly as possible the word they thought they were hearing, and then write down their confidence rating.

\section{RESULTS AND DISCUSSION}

\section{Are naming times similar to the times found in other on-line tasks?}

Before considering whether the nontimed gating task taps the sequential analysis of the speech input, we have to establish that naming times obtained from the gating task are similar to times found in various on-line tasks. Our diagnostic here is the speed with which subjects name the target word. Responses need to be as fast as those obtained in tasks which we already assume reflect on-line processes.

To calculate naming times we subtracted the duration of each fragment from the total latency (measured from word onset) for all responses in which the correct target was produced. ${ }^{9}$ This gave us an estimate of the time subjects took to name the fragment. We then pooled all naming latencies produced at the IPs in all conditions, and at the RPs in all conditions. The mean naming latency for IPs was $487 \mathrm{msec}$, and that for RPs was $469 \mathrm{msec}^{10}$ These compare favorably with RTs obtained in other paradigms. The most direct comparisons are with the results of an auditory lexical decision experiment (Marslen-Wilson, 1984) and a mispronunciation detection study (Ottevanger, 1983), in which responses were measured from RP. In the first study, lexical decision RTs averaged 450 msec from RP, and in the second, mispronunciation detection latencies averaged $633 \mathrm{msec}$ from RP. It is also worth noting the similarities between the present RTs and those collected in various less directly comparable on-line tasks (in that responses are not measured from the RP). For example, Tyler and Marslen-Wilson (1977) reported latencies of $537 \mathrm{msec}$ to name a visual probe presented at the offset of a sentence fragment. Phoneme monitoring latencies have been found to be between 400 and 450 msec (Blank \& Foss, 1978; Frauenfelder, Segui, \& Mehler, 1980); visual lexical decision times, around
$700 \mathrm{msec}$ (Taft \& Forster, 1975; Wright \& Garrett, 1984); and mispronunciation detection latencies, at least $650 \mathrm{msec}$ (Cole \& Jakimik, 1978). The timed version of the gating task produces latencies which are within the range of those elicited in a variety of other tasks which are usually regarded as on-line measures.

\section{Recognition points}

We will consider the RP data first because we have argued elsewhere (Tyler \& Wessels, 1983) that the RP provides a more accurate estimate than the IP of the point at which a word is identified. This is because the RP closely approximates the RP of a word as defined by the "cohort theory" (Marslen-Wilson \& Welsh, 1978), that is, the point at which the word becomes uniquely distinguishable from all other words in the language beginning with the same initial sound sequence. We found that the RPs of a set of words heard in varying sentential contexts corresponded better than did the IPs to the point at which there was only one remaining member of the original cohort. The mean number of inflected and derived word forms remaining at the RPs was 2.8 , which is close to the cohort theory's predicted value of 1.0 , whereas the mean number of derived and inflected forms at the IPs was 4.7."

For the present analyses, we calculated the RP for each item in each condition by locating the mean gate at which subjects identified the target with $80 \%$ or greater confidence. We chose $80 \%$ as our criterial level of confidence because, although confidence should be high, it cannot be $100 \%$ because most subjects do not use the entire rating scale. On the basis of a number of studies (e.g., Marslen-Wilson, 1984; Tyler \& Wessels, 1983), 80\% confidence has been found to produce reliable results. Recognition points based on $80 \%$ confidence correlate well with phoneme-monitoring reaction times (MarslenWilson, 1984) and with the point at which a word becomes the sole surviving member of the initial cohort (Tyler \& Wessels, 1983).

The mean RPs, together with the mean RPs for the same 17 items in the nontimed study (Tyler \& Wessels, 1983), are presented in Figure $1 .{ }^{12}$ Both sets of data were entered into an analysis of variance (ANOVA) with items as a random effect. Items were crossed with the five experimental conditions and with task (timed vs. nontimed). The RPs in the timed experiment were earlier than in the nontimed experiment $[F(1,16)=18.21, p<.001]$ by an average of $24 \mathrm{msec}$. However, it is only in the two minimal semantic conditions that the difference ( 45 and $30 \mathrm{msec}$ ) is significant. In all other conditions the difference $(16,21$, and $5 \mathrm{msec})$ was not significant. This is reflected in a significant condition $\times$ task interaction $[F(4,64)=3.104, p<.05]$, and in post hoc comparisons (Newman-Keuls) that were significant $(p<.01)$ for the two minimal semantic conditions but not for the other conditions. These data show that semantic context has a slightly greater effect in the timed than in the nontimed 
task. Having to make a rapid response may speed up the process of integrating the sensory input with the prior semantic and syntactic context.

If the nontimed task does reflect on-line processes, then it is crucial that the relative effect of syntactic and semantic constraints should not differ between tasks. In the nontimed task, strong syntactic constaints reduced the amount of sensory input required for recognition only slightly, whereas a minimal semantic context reduced the amount of sensory input considerably. The same pattern was found in the timed task. For this analysis, the RPs for the nocontext condition provided a baseline for the evaluation of context effects. The mean RP for each item in each of the four context conditions was subtracted from the mean RP for each item in the no-context condition. The results of the ANOVA performed on these difference scores (with syntax and semantics as fixed effects) showed that syntactic constraints reduced the amount of sensory input by $52 \mathrm{msec}[\mathrm{F}(1,16)=9.05, \mathrm{p}<.01]$ and semantics reduced it by $94 \mathrm{msec}[\mathrm{F}(1,16)=19.1, \mathrm{p}<.001]$. For the 17 relevant items in the nontimed gating experiment, syntax had an effect of $32 \mathrm{msec}[\mathrm{F}(1,16)=5.51$, $p<.05]$ and semantics had an effect of $82 \mathrm{msec}[F(1,16)$ $=21.84, \mathrm{p}<.001]$.

In the timed gating experiment, then, syntactic and semantic constraints had a slightly larger effect than in the nontimed experiment. Most importantly, however, the relative effectiveness of each source of constraint did not differ across experiments (task $\times$ condition: $F<1$ ), showing that the two versions of the gating task are not differentially sensitive to these variables.
Finally, we have to consider the number of word candidates remaining at the RPs for each condition. According to the cohort theory (Marslen-Wilson \& Tyler, 1980), only a single member of the original cohort should remain at the RP, if the RP does indeed mark the point at which a word becomes uniquely distinguishable from all other words in the language. For the nontimed data, we found that RPs correlated very well with uniqueness point. There was, on average, just over one stem morpheme (mean $=1.18$ ) remaining at the RP in each condition (Tyler \& Wessels, 1983). A reanalysis of the word candidates, using these slightly earlier RPs, gave essentially identical results (mean $=1.3$ ).

\section{lsolation points}

To calculate IPs for each item in each condition, we located the mean gate at which subjects correctly identified the target and did not subsequently change their minds. The IPs for the same 17 items from the nontimed study were also calculated. These values were entered into an ANOVA with items as a random effect. Items were crossed with the five experimental conditions and with task (timed gating vs. nontimed gating). The mean IPs for the five conditions in each task are presented in Figure 1.

The isolation points in the timed gating were, on average, $30 \mathrm{msec}$ later than in the nontimed gating $[F(1,16)=186.27, p<.001]$. But the effect of different conditions was the same in both tasks (task $\times$ condition interaction was not significant) $[F(4,64)=2.020$, $p=.10]$. In both studies, the amount of sensory input

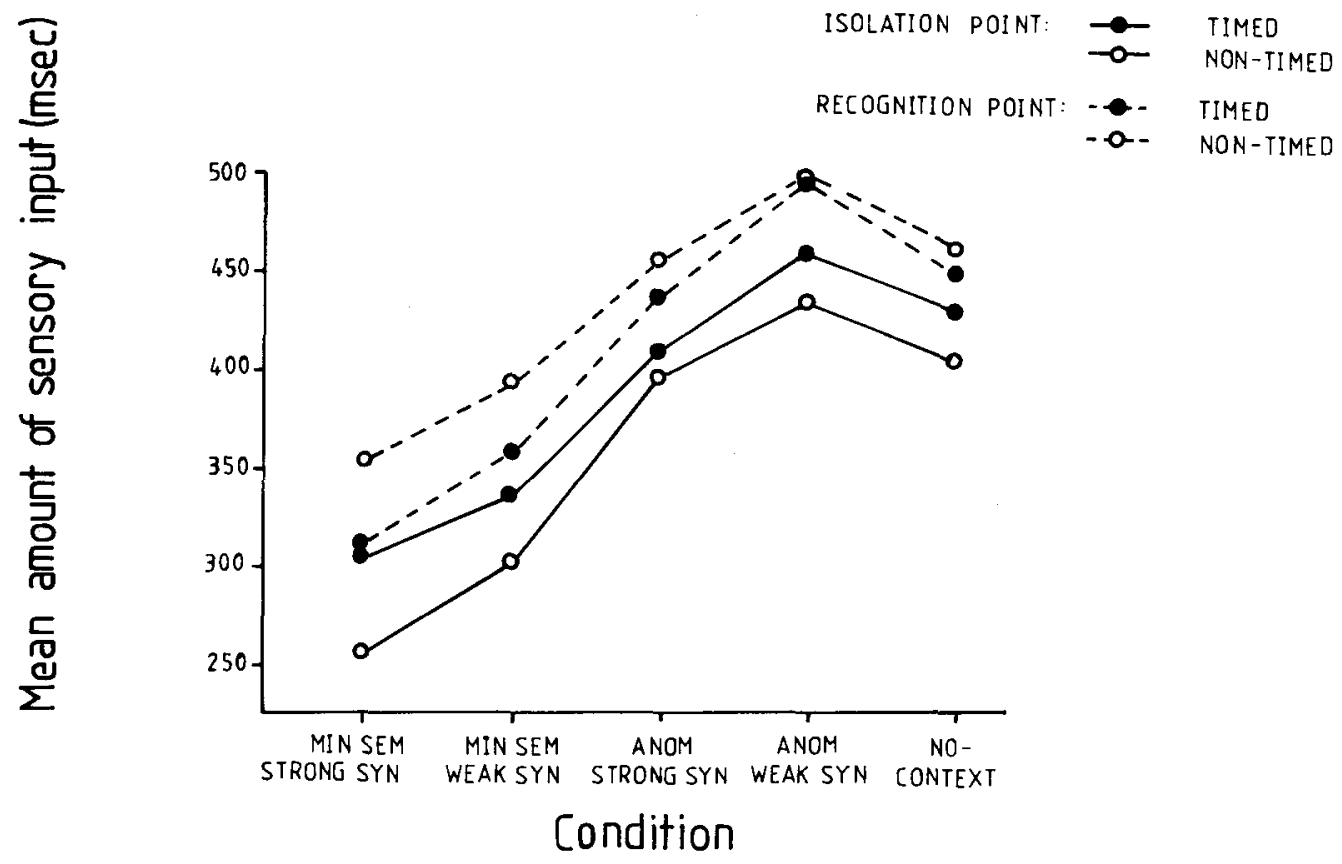

Figure 1. Mean isolation and recognition points for each condition in the timed and nontimed experiments. 
needed to correctly identify the word was less in the two minimal semantic conditions (timed, $326 \mathrm{msec}$; nontimed, $286 \mathrm{msec}$ ) than in either the no-context (timed, $432 \mathrm{msec}$; nontimed, $405 \mathrm{msec}$ ) or anomalous context (timed, $436 \mathrm{msec}$; nontimed, $413 \mathrm{msec}$ ) conditions.

To evaluate the extent to which context significantly reduced the amount of sensory input needed for identification, we subtracted each IP in the four context conditions from the corresponding IP in the no-context condition. Another ANOVA was performed on these differences, with syntax and semantics as fixed effects. Once again, the analysis showed that there were no differences between the two tasks $(F<1)$. There was a main effect of both syntax and semantics, with a large difference in the size of each effect. Whereas semantic constraints reduced the amount of sensory input by $118 \mathrm{msec}$ $[\mathrm{F}(1,16)=20.199, \mathrm{p}<.001]$, syntactic constraints reduced it by only $44 \mathrm{msec}[\mathrm{F}(1,16)=8.227, \mathrm{p}=.011]$. The effect of each type of context was unaffected by the strength of the constraints imposed by the other type of context [the syntax $\times$ semantics interaction was not significant $(F<1)$ ]. Finally, the size of the effects of syntax and semantics did not differ between tasks [task $x$ syntax $\times$ semantics interaction was not significant: $\mathrm{F}(1,16)=1.619, \mathrm{p}<.20]$.

These analyses show that the relative effects of syntactic and semantic constraints on reducing the amount of sensory input needed for isolating a word are not affected by the type of task. Syntactic constraints had a much smaller effect than semantic constraints, whether or not subjects produced a response rapidly. We also found that isolation times were slightly later in the word in the timed than in the nontimed gating task. This was possibly due to a reduction in subjects' strategic responses in the timed version of the task. When subjects have to respond rapidly, the point at which they isolate a word is closer to the point at which it is the only remaining member of the cohort.

\section{CONCLUSIONS}

The timed and nontimed versions of the gating task produce very similar results in terms of the earliness with which words are recognized and the effects of contextual constraint. Although we found that isolation and recognition points were displaced in the timed, compared to the nontimed, version, the effect was very small.

The crucial finding is that the influence of syntactic and semantic constraints was the same in both studies, with strong syntactic form-class constraints having a much smaller effect than even very weak semantic constraints. There was no difference between the tasks in the extent to which each source of constraint reduced the amount of sensory input needed for correct identification of a word.

This establishes that the nontimed task is as sensitive as the timed task for investigating the processes involved in spoken word recognition. Moreover, since latencies to name the target words in the timed version were com- parable to RTs obtained in a variety of on-line tasks, we can be reasonably confident that both studies tap the processes involved in the real-time analysis of the speech signal. However, because the nontimed version of the task is much less time-consuming to administer and requires far fewer subjects, it is preferable to use this rather than the timed version of the task.

Given that gating responses are not distorted either by the lag between input and response or by successive presentation of fragments, we should consider the advantages of the nontimed task as a task that taps on-line processes. It has distinct advantages over those on-line tasks in which the only response obtained from the subject is a RT. What is missing from purely RT tasks is the qualitative data that the gating task provides. The subject's response at each successive fragment tells us what information has been extracted from the sensory signal, what aspects of the changing input are used by the listener to identify the word, and how this information is integrated with the prior context. The shadowing task (MarslenWilson, 1973, 1985; Marslen-Wilson \& Welsh, 1978) is one of the few other tasks which provide a similarly rich source of information about the analyses performed by the listener on the sensory input as it accumulates over time.

\section{REFERENCES}

Blank, M., \& Foss, D. (1978). Semantic facilitation and lexical access during sentence processing. Memory \& Cognition, 6, 644-652.

COLE, R., \& JAKIMIK, J. (1978). Understanding speech: How words are heard. In G. Underwood (Ed.), Strategies of information processing. London: Academic Press.

Cotton, S. , \& Grosjean, F. (1984). The gating paradigm: A comparison of successive and individual presentation formats. Perception \& Psychophysics, 35, 41-48.

FORSTER, K. I. (1979). Levels of processing and the structure of the language processor. In W. E. Cooper \& E. C. T. Walker (Eds.), Sentence processing: Psycholinguistic studies presented to Merrill Garrett. Cambridge, MA: MIT Press.

Frauenfelder, U., Segui, J., \& Mehler, J. (1980). Monitoring around the relative clause. Journal of Verbal Learning \& Verbal Behavior, 19, 328-337.

GROSJEAN, F. (1980). Spoken word recognition processes and the gating paradigm. Perception \& Psychophysics, 28, 267-283.

MARSLEN-Wilson, W. D. (1973). Linguistic structure and speech shadowing at very short latencies. Nature, 244, 522-523.

MARSLEN-Wilson, W. D. (1984). Parallel processing in spoken word recognition. Unpublished manuscript, Max-Planck-Institut für Psycholinguistik

MARSLEN-WILSON, W. D. (1985). Speech shadowing and speech comprehension. Speech Communication, 4, 55-73.

MARSLEN-WILSON, W. D., \& TYLER, L. K. (1980). The temporal structure of spoken language understanding. Cognition, 8, 1-71.

Marslen-Wilson, W. D., \& TYleR, L. K. (1981). Central processes in speech understanding. Philosophical Transactions of the Royal Society, London, B295, 317-332.

Marslen-Wilson, W. D., \& Welsh, A. (1978). Processing interactions and lexical access during word recognition in continuous speech. Cognitive Psychology, 10, 29-63.

OhMAN, S. (1966). Perception of segments of VCCV utterances. Journal of the Acoustical Society of America, 40, 979-988.

OTTEVANGER, I. (1983). The detection of mispronunciations and the influence of context. In M. P. R. van den Broeke \& A. Cohen (Eds.), Proceedings of the Tenth International Congress of Phonetic Sciences (Vol. 11b, pp. 486-490). Dordrecht, The Netherlands. 
Pollack, I. \& PicketT, J. (1963). The intelligibility of excerpts from conversation. Language \& Speech, 6, 165-171.

Salasoo, A., Pisoni, D. (1985). Interaction of knowledge sources in spoken word identification. Journal of Memory \& Language, 24, 210-231.

Sternberg, S., Monsell, S., Knoll, R. L., \& Wright, C. E. (1979). The latency and duration of rapid movement sequences: Comparisons of speech and typewriting. In G. Stelmach (Ed.), Information processing in motor control and learning. New York: Academic Press.

TAFT, M., \& FORSTER, K. (1975). Lexical storage and retrieval of prefixed words. Journal of Verbal Learning \& Verbal Behavior, 14, 638-647.

TYLER, L. K. (1984). The structure of the initial cohort: Evidence from gating. Perception \& Psychophysics, 35, 417-428.

TYLER, L. K., \& MARSLEN-WiLSON, W. D. (1977). The on-line effects of semantic context on syntactic processing. Journal of Verbal Learning \& Verbal Behavior, 16, 683-692.

TYleR, L, K., \& WesSELS, J. (1983). Quantifying contextual contributions to word recognition processes. Perception \& Psychophysics, 34, 409-420.

WrIGHT, B., \& GARRETT, M. (1984). Lexical decision in sentences. Memory \& Cognition, 12, 31-45.

\section{NOTES}

1. This task was originally used by Pollack and Pickett (1963) and Ohman (1966)

2. One of the objections raised against so-called "off-line tasks" is that not only is the response delayed in time relative to the relevant part of the input, but other material intervenes between stimulus and response.

3. This meant that only a subset of the fragments used in the original study was used in the present experiment.

4. These were the 17 items for which we had established, by means of a posttest (Tyler \& Wessels, 1983), that /te/ was perceived by listeners and therefore provided the appropriate strong syntactic constraints.

5. Tapes for this study were copies of the original tapes used in the nontimed study.

6. A pretest, using an auditory cloze procedure, established that the semantic contexts in these conditions were indeed only minimally constraining. In this pretest, listeners heard the first $100 \mathrm{msec}$ of each target in the four context conditions. This restricted the set of words likely to be produced and provided a more conservative test of the target's predictability than if none of the target had been presented. Subjects' responses were scored by two independent judges according to the following values: $1=$ identical with the target; $2=$ synonym of target; 3 = related to target; $4=$ contextually appropriate but unrelated to target; $5=$ contextually inappropriate and unrelated to target. The mean ratings for the two semantically normal conditions were 3.95 and 3.96 , indicating that although responses were contextually appropriate, subjects rarely produced the target word itself. For the two semantically anomalous conditions, the ratings were 4.88 and 4.97 , showing that responses were unrelated to the intended target.
7. Example of the materials in Dutch:

Target word: profiteren

(a) Min sem/strong syn: De afspraak met de tandarts gaat niet door. Jan probeert te. .

(b) Min sem/weak syn: De afspraak met de tandarts gaat niet door. Jan kan. .

(c) Anom/strong syn: De adem met de leugen schuift pas door. Het terras tracht te. .

(d) Anom/weak syn: De adem met de leugen schuift pas door. Het terras wil. .

Literal English gloss (the syntactic constraints do not function the same way in English as they do in Dutch):

Target word: to benefit

(a) The appointment with the dentist goes not through. John tries to. . .

(b) The appointment with the dentist goes not through. John can. .

(c) The breath with the lie shuffles only through. The terrace tries to. . .

(d) The breath with the lie shuffles only through. The terrace will. .

8. We selected five fragments in order to reduce the experiment to a manageable size.

9. We did not analyze nontarget responses because these did not form a homogeneous set in terms of duration and it is known that the time to produce a word varies as a function of its duration (Sternberg, Monsell, Knoll, \& Wright, 1979).

10. The mean RTs for each condition were: Min sem/strong syn, $514 \mathrm{msec}$; Min sem/weak syn, $498 \mathrm{msec}$; Anom/strong syn, $437 \mathrm{msec}$; Anom/weak syn, $421 \mathrm{msec}$; Isolation, $419 \mathrm{msec}$. The differences be tween RTs were not analyzed because there were differences in the length of the fragments in each condition, making any such comparison complex. Differences in RTs in the various conditions are not important for the point we are making here.

11. If we consider only base morphemes, the count of 1.18 word candidates remaining at the RP fits even better with the cohort theory's predictions.

12. Recognition points were calculated in the same way in both studies-that is, the mean gate at which subjects correctly identified the word with at least $80 \%$ confidence. However, in the timed study the RP was based upon a subset of the fragments used in the nontimed study. This reduction in the number of gates did not affect the calculations because the gates for the timed study were chosen to be around the point at which the word was correctly identified in the nontimed experiment. Using a subset of gates would have affected RP calculations only if subjects had been unable to identify the word at any of the gates.

(Manuscript received February 18, 1985; revision accepted for publication August 21, 1985.) 